\title{
Artificial Intelligence-Based Optimal PID Controller Design for BLDC Motor with Phase Advance
}

\author{
Manoon Boonpramuk ${ }^{1}$, Satean Tunyasirut ${ }^{2}$, Deacha Puangdownreong ${ }^{3}$ \\ ${ }^{1,2}$ Department of Electrical Engineering, Faculty of Engineering, Pathumwan Institute of Technology, Thailand \\ ${ }^{3}$ Department of Electrical Engineering, Faculty of Engineering, South-East Asia University, Thailand
}

\begin{tabular}{|c|c|}
\hline Article Info & ABSTRACT \\
\hline Article historys: & This paper proposes the artificial intelligence (AI)-based optimal PID \\
\hline Received Jun 1, 2019 & controller design optimization of brushless direct current (BLDC) motor speed \\
\hline Revised Sep 9, 2019 & speed adjustment of the BLDC motor by phase advance technique. In this \\
\hline Accepted Nov 27, 2019 & $\begin{array}{l}\text { paper, two selected AI algorithms, i.e., the adaptive tabu search (ATS) and the } \\
\text { intensified current search (ICS) are conducted as the optimizer for the PID }\end{array}$ \\
\hline Keywords: & $\begin{array}{l}\text { controller design. The proposed control system is simulated by } \\
\text { MATLAB/SIMULINK. Results obtained by the ATS and ICS will be }\end{array}$ \\
\hline $\begin{array}{l}\text { Artificial Intelligence } \\
\text { PID Controller } \\
\text { BLDC Motor }\end{array}$ & $\begin{array}{l}\text { compared with those obtained by the Ziegler-Nichols (ZN) tuning rule and the } \\
\text { genetic algorithm (GA). It shows that the speed response of the BLDC motor } \\
\text { by phase advance with the PID controller optimized by the ICS outperforms } \\
\text { better than the ZN, GA and ATS. }\end{array}$ \\
\hline
\end{tabular}

Copyright (C) 2019 Institute of Advanced Engineering and Science. All rights reserved.

\section{Corresponding Author:}

Manoon Boonpramuk,

Department of Electrical Engineering, Faculty of Engineering,

Pathumwan Institute of Technology, Bangkok, Thailand.

Email: amanoonz@gmail.com

\section{INTRODUCTION}

The brushless direct current (BLDC) motor is a kind of synchronous motor having permanent magnets on the rotor and stator winding. It has been broadly utilized in automotive, hard disk, robotics, vehicle, aerospace, home appliance and instrumentation. The BLDC motor has many advantages over the induction motor including simple structure, low size, excellent efficiency, less maintenance, low noise and wide speed range [1] -[3]. In the future, motor controllers need to be improved for application targets through simple and economical design.

The BLDC motor can be expanded to operation speed range more than base speed by phase advance [4]. This allows the utilization of BLDC motor in various applications for high speed range. So, it is necessary to have a controller that can improve performance for developing three phases of the BLDC motor drive. The PID controller is extensively used in the BLDC motor drive because of the effectiveness and simple structure [5], [6]. The parameters of PID controller are very essential for the performance of motor control system, particularly in motor device with nonlinearity and large inert [7]. From the previous researches [4], [8]-[11], the BLDC motor system with phase advance is regulated by conventional control methods. It is found that the performance of motor has steady state error and slow speed response. Therefore, the speed response of the BLDC motor system with phase advance can be done effectively by optimizing the values of PID controller parameter using artificial intelligence (AI) algorithms. Furthermore, the applications of AI algorithms for PID controller of the BLDC motor system with phase advance have not been presented in the previous researches [4], [8]-[11]. The AI algorithms have been extensively accepted for the controller design in many industrial applications [12]. For example, designing of BLDC rotor speed by fuzzy logic [13], genetic algorithm (GA) for controller design [14], self-turning the PID controller using GA [15], controller design using adaptive tabu search (ATS) [16], aircraft electric control by ATS [17] and control synthesis using current search (CS) [18], 
[19]. Hence, this paper presents the use of AI algorithms for tuning the PID parameters $\left(K_{P}, K_{i}\right.$ and $\left.K_{d}\right)$ for controlling the BLDC motor with phase advance.

In this paper, there are divided six sections. Firstly, the introduction is described. Secondary, the details of the modeling of BLDC motor and phase advance technique are presented. Thirdly, the details of AI algorithms are demonstrated. Fourthly, the application of selected AI algorithms is tuned the PID parameters for the BLDC motor system. Fifthly, the simulation results are illustrated. Finally, the conclusions are described.

\section{MODELING OF BLDC MOTOR AND PHASE ADVANCE TECHNIQUE}

\subsection{Modeling of BLDC motor}

The equivalent circuit model of the BLDC motor is illustrated as shown in Figure 1. The modeling of BLDC motor can be performed in equation (1) [1], [2].

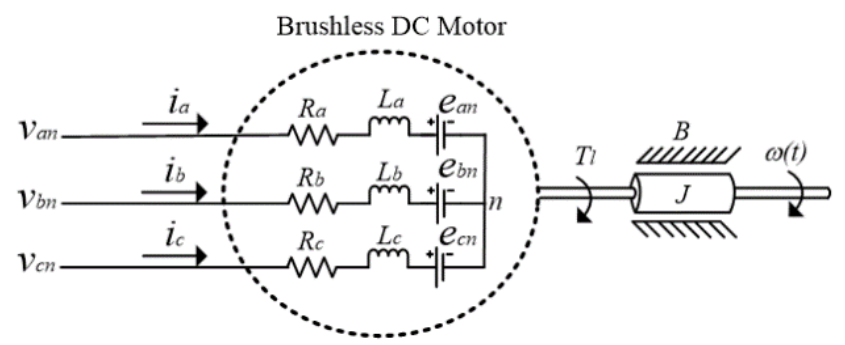

Figure 1. Equivalent circuit model

In Figure 1, it consists of inductance, back emf and resistance, where $v_{a n}, v_{b n}$ and $v_{c n}$ are the output phase voltages, $i_{a}, i_{b}$ and $i_{c}$ represent the phase currents, $L_{a}, L_{b}$ and $L_{c}$ are the phase inductances, $e_{a n}, e_{b n}$ and $e_{c n}$ are phase back emfs, $R_{a}, R_{b}$ and $R_{c}$ are the phase resistances of rotor.

$$
\left.\begin{array}{l}
v_{a n}=R_{a} i_{a}+L_{a} \frac{d i_{a}}{d t}+e_{a n} \\
v_{b n}=R_{b} i_{b}+L_{b} \frac{d i_{b}}{d t}+e_{b n} \\
v_{c n}=R_{c} i_{c}+L_{c} \frac{d i_{c}}{d t}+e_{c n}
\end{array}\right\}
$$

The trapezoidal back emfs in equation (2) are related to a function of rotor position, where $\theta_{e}$ and $K_{w}$ are the electrical rotor angle and the back emf constant of each phase, $\omega_{r}$ denotes the motor angular velocity in $\mathrm{rad} / \mathrm{s}$ and $f_{a}, f_{b}$ and $f_{c}$ represent the function of rotor position.

$$
\left.\begin{array}{l}
e_{a n}=K_{w} \omega_{r} f_{a}\left(\theta_{e}\right) \\
e_{b n}=K_{w} \omega_{r} f_{b}\left(\theta_{e}-2 \pi / 3\right) \\
e_{c n}=K_{w} \omega_{r} f_{c}\left(\theta_{e}-4 \pi / 3\right)
\end{array}\right\}
$$

The electromagnetic torque is a simple equation of phase current and phase back emf as expressed in equation (3), where $T_{e}$ is electromagnetic torque and $T_{e a}, T_{e b}$ and $T_{e c}$ represent phase electric torque. The relation between the speed and the torque are stated in equation (4), where $T_{l}$ is an indicative of load torque in N.m, $J$ denotes the moment of inertia in $\mathrm{kg}-\mathrm{m}^{2}$ and $B$ is the static friction in N.m-s/rad.

$$
\begin{aligned}
& T_{e}=T_{e a}+T_{e b}+T_{e c}=\frac{\left[e_{a n} i_{a}+e_{b n} i_{b}+e_{c n} i_{c}\right]}{\omega_{r}} \\
& T_{e}=J \frac{d \omega}{d t}+B \omega+T_{l}
\end{aligned}
$$

\subsection{Phase advance}

The phase advance technique is a common control of the phase current to lead the phase back emf. It can increase the speed of BLDC motor over the base speed. Figure 2 shows the phase currents shifted by the angle of $\alpha_{a d v}$ to phase back emf. The phase currents can be varied from $0^{\circ}$ to $60^{\circ}$, electrical degree [8]-[10]. 


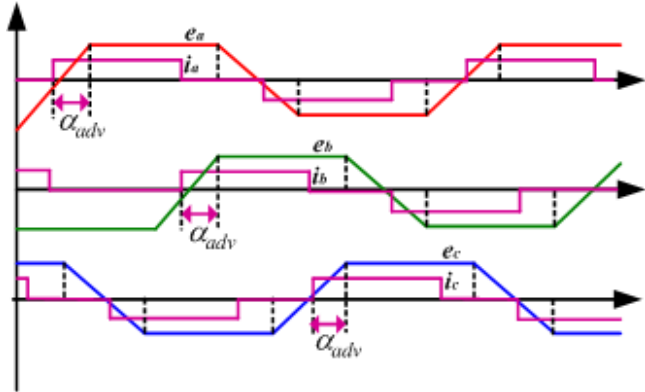

Figure 2. Waveforms of phase current and phase back emf

The phase advance is described in equation (5), where $L_{s}$ is an indicative of phase inductance, $\alpha_{a d v}$ is the angle of phase advance, $V_{d c}$ is an indicative of voltage source, $n$ is rotor speed and $I_{p h}$ denotes the phase current.

$$
\alpha_{a d v}=\omega_{r} \frac{L_{s} I_{p h}}{V_{d c}}, \quad \omega_{r}=2 p n \pi
$$

In Figure 3, it shows the three phase inverter for BLDC motor drive. In this work, the proposed drive system composes of three phase inverter, switch control signals, Hall effect sensors, BLDC motor and DC voltage source. The switching states of three phase inverter based on Hall effect signals are visualized in Figure 4.

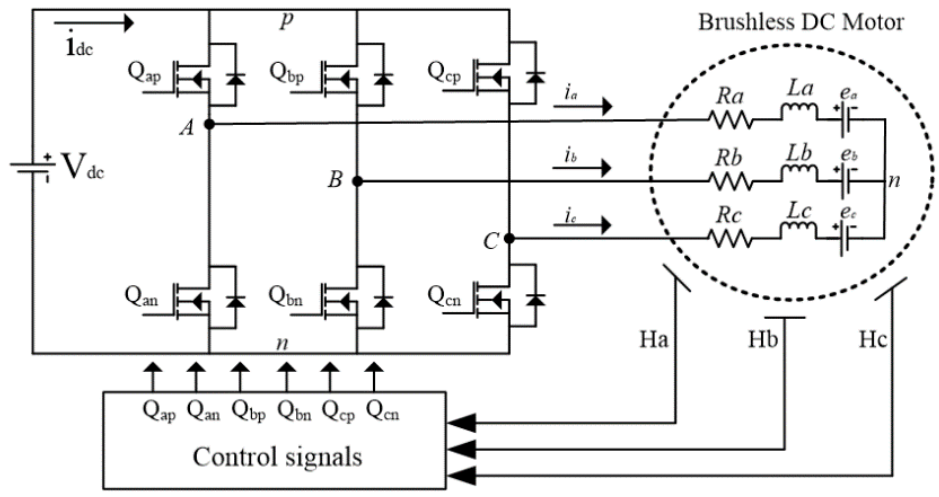

Figure 3. Three phase inverter of BLDC motor drive

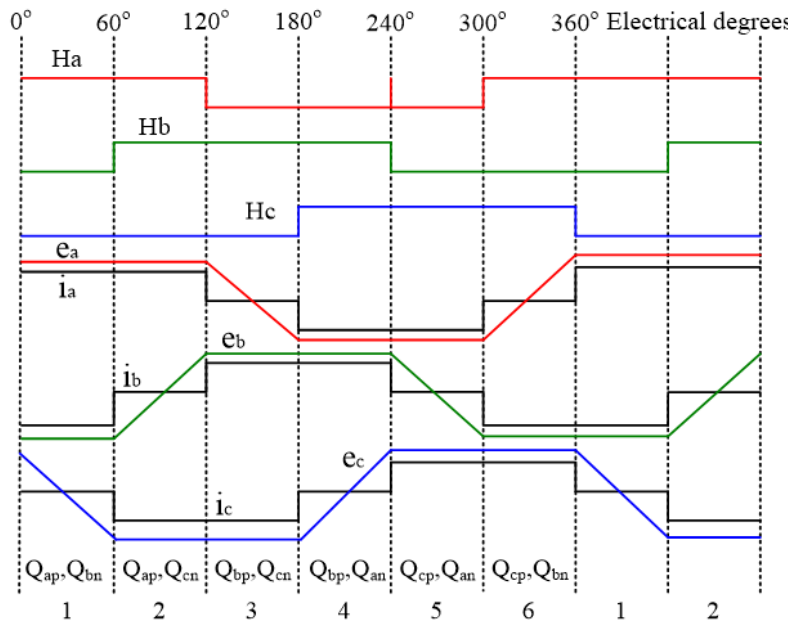

Figure 4. Hall effect signals, switching states and back emfs 
Table 1 shows the switching states for the BLDC motor drive. Each step has an interval of $60^{\circ}$ ,electrical degree.

Table 1. Switching states

\begin{tabular}{cccccc}
\hline Step & Interval & Switch & Phase A & Phase B & Phase C \\
\hline 1 & $0^{\circ}-60^{\circ}$ & $\mathrm{Q}_{\text {ap }}, \mathrm{Q}_{\text {bn }}$ & + & - & 0 \\
2 & $60^{\circ}-120^{\circ}$ & $\mathrm{Q}_{\text {ap }}, \mathrm{Q}_{\mathrm{cn}}$ & + & 0 & - \\
3 & $120^{\circ}-180^{\circ}$ & $\mathrm{Q}_{\mathrm{bp}}, \mathrm{Q}_{\mathrm{cn}}$ & 0 & + & - \\
4 & $180^{\circ}-240^{\circ}$ & $\mathrm{Q}_{\mathrm{bp}}, \mathrm{Q}_{\text {an }}$ & - & + & 0 \\
5 & $240^{\circ}-300^{\circ}$ & $\mathrm{Q}_{\mathrm{cp}}, \mathrm{Q}_{\text {an }}$ & - & 0 & + \\
6 & $300^{\circ}-360^{\circ}$ & $\mathrm{Q}_{\mathrm{cp}}, \mathrm{Q}_{\mathrm{bn}}$ & 0 & - & + \\
\hline
\end{tabular}

Figure 5 shows Hall effect signals which effect the switching states of three phase inverter. The phase advance adjusts the Hall effect signals ( $\mathrm{Ha}^{*}, \mathrm{Hb}^{*}$ and $\left.\mathrm{Hc}^{*}\right)$ leading the previous Hall effect signals $(\mathrm{Ha}, \mathrm{Hb}$ and $\mathrm{Hc})$.

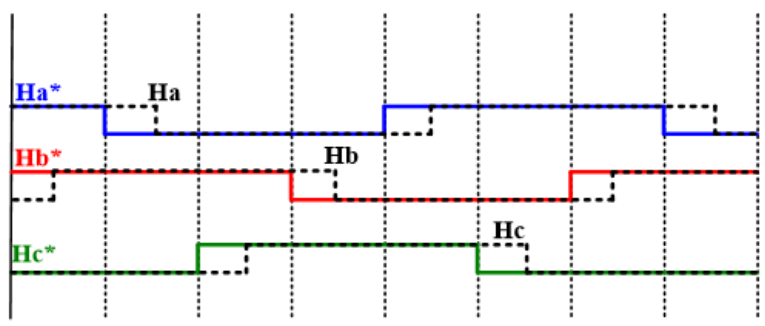

Figure 5. Waveforms of Hall effect signal

\section{ARTIFICIAL INTELLIGENCE}

Recently, AI algorithms have been broadly utilized to solve combinatorial and engineering problems. In this section, the AI algorithms consisting of the intensified current search (ICS) and the ATS are briefly reviewed.

\subsection{ICS algorithm}

The CS is one of the AI algorithms based on the current divider of the electric circuits and network systems [18], [19]. Theoretically, the CS only composed the memory list (ML). For solving the computational problems, the ICS algorithm has been modified version by adding the adaptive radius (AR) and the adaptive neighborhood (AN). In order to find the optimal solution, the ICS is able not only to escape the local entrapment but also to speed up the search process in the search space. The movement of the ICS over search space is illustrated in Figure 6. The pseudo code of the ICS is described in Figure 7 [20], [21].

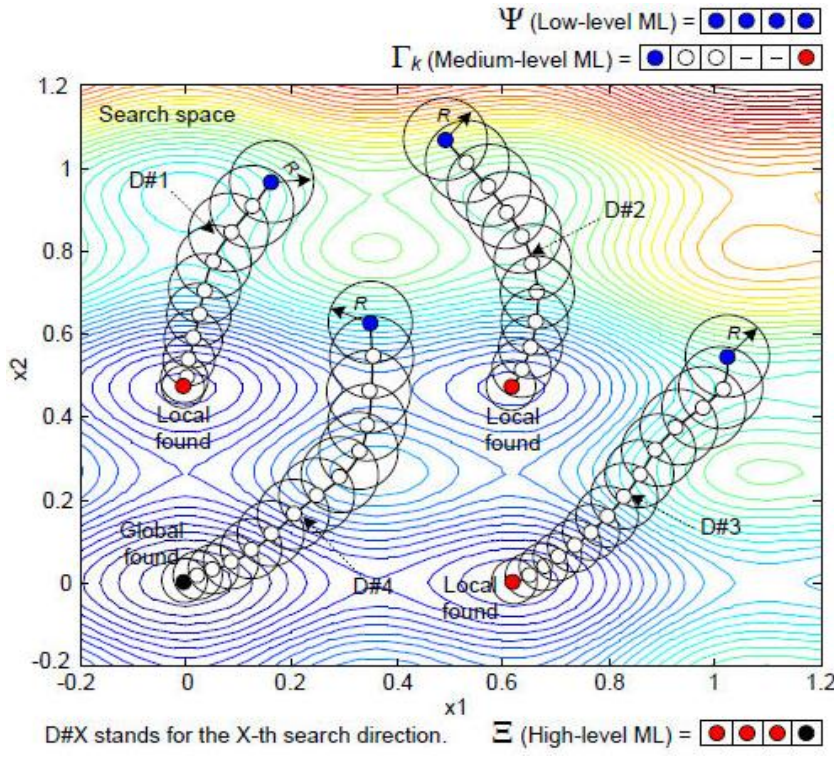

Figure 6. Movement of the ICS algorithm [20], [21] 
Start

Step 1: The objective function, the search space, the number of initial solution and the number the neighborhood members are initial as $f(x), x=\left(x_{1}, x_{2}, \ldots x_{d}\right), \Omega$, $N$ and $n$ respectively.

Step 2: The memory list, $\mathrm{ML}\left(\Psi, \Gamma_{\mathrm{K}}, \Xi\right)=\varnothing$, the search radius $R, k=j=1$, $x_{i}$ is random within $\Omega$.

Step 3: The number of maximum allowance of solution cycling $j_{\max }$ is initial, $x_{0}=x_{k}$ as initial solution.

Step 4: The $X_{\text {global }}=X_{\text {local }}=x_{0}$ is evaluated by the objective function $f\left(x_{i}\right)$ and then the solution $x_{i}$ is set in the $\Psi$.

Step 5: while ( $k \leq N$ or termination criteria (TC) )

Let $x_{0}=x_{k}$ be initial solution

for $j$ to $j_{\max }$

$x_{i}$ is random around $x_{0}$ in the $R$

$f(x)$ is evaluated then $x *$ is defined as the best solution

if $f\left(x^{*}\right)<f\left(x_{0}\right)$ else $x_{0}$ is save to $\Gamma_{\kappa}$, update $x_{0}=x *$ and set $j=1$

end if $x *$ is save to $\Gamma_{\mathrm{\kappa}}$, and update $j=j+1$

Activate AR by $R=\rho R, 0<\rho<1$

end for Invoke AN by $n=\alpha n, 0<\alpha<1$

The $X_{\text {best }}=x_{0}$ is set and $X_{\text {global }}$ is save to $\Xi$

if $f\left(X_{\text {local }}\right)=f\left(X_{\text {global }}\right)$ then $X_{\text {global }}=X_{\text {local }}$

end if

end while

Then $k=k+1, j=1$ and $x_{0}=x_{k}$ as initial solution

Step 6: Best solution found.

Stop

Figure 7. Pseudo code of ICS [20], [21]

\subsection{ATS algorithm}

The ATS was firstly launched in 2002 [22], [23] as one of the AI algorithms. It has been modified version of the TS [24], [25] and based on an interactive neighborhood search approach for solving combinatorial and nonlinear problems. The mechanisms of ATS have the adaptive radius (AR) and back tracking (BT). To speed up the search process of ATS, AR mechanism is utilized to intensity. Moreover, the BT mechanism is able to conduct to escape the local entrapments. The movement of ATS over search space can be illustrated in Figure 8. The pseudo code of the ATS is shown in Figure 9 [22], [23].

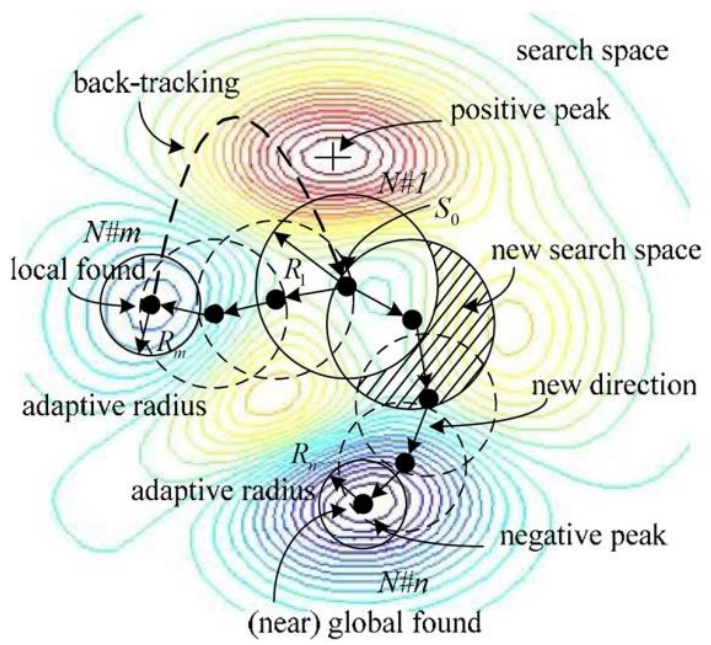


Figure 8. Movement of the ATS algorithm [22], [23]

Start

Step 1: The objective function, the search space, Tabu list, search radius and termination criteria are initial as $f(s), s=\left(s_{1}, s_{2}, \ldots, s_{2}\right), \Omega$, TL, $R$ and $\mathrm{TC}$, respectively.

Step 2: The solution, $N$ is generated randomly around $s_{0}$ within $\Omega$ and the occurred local entrapment $L_{f l a g}$

Step 3: The objective function, $f\left(s_{0}\right)$ is evaluated.

Step 4: while( TC);

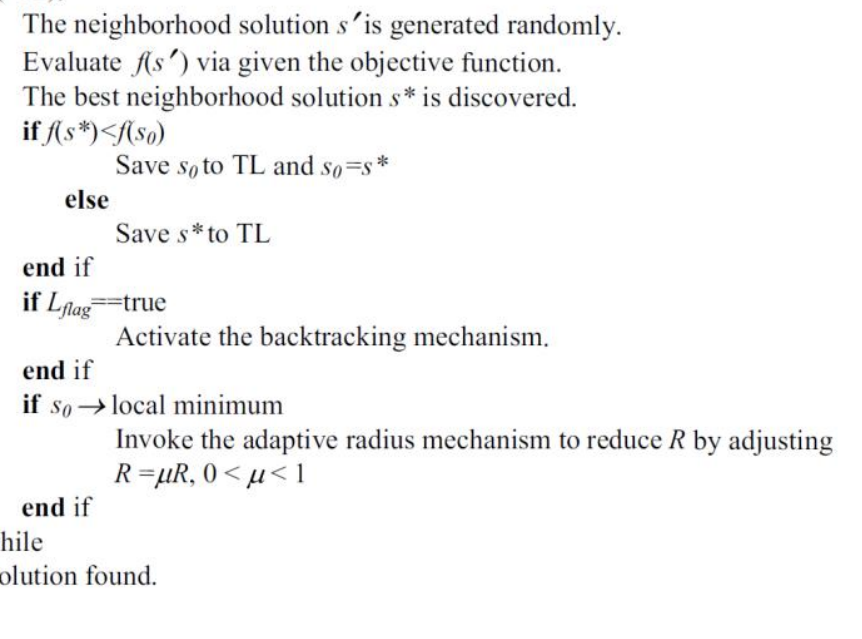

Figure 9. Pseudo code of ATS [22], [23]

\section{PID CONTROLLER OF BLDC MOTOR}

The PID controller was firstly conducted to industrial applications in 1939 [26]. It has been extensively used in the industrial control systems because of its simple structure and effectiveness. Figure 10 shows the conventional control loop of PID controller, where $R(s)$ is reference input signal, $E(s)$ is an error signal, $U(s)$ is control signal, $D(s)$ is disturbance signal and $C(s)$ is output response, respectively. $G_{c}(s)$ is the PID controller model and $G_{p}(\mathrm{~s})$ is the BLDC motor model. Referring to Figure 10, $G_{c}(s)$ will receive $E(s)$ different between $R(s)$ and $C(s))$ and generate $U(s)$ for controlling $G_{p}(\mathrm{~s})$ to provide desired $C(s)$ according to $R(s)$, whereas regulating $D(s)$, simultaneously. The liner transfer function of the BLDC motor plant can be stated in equation (6) [27], where $\tau_{A}$ is the driver time constant, $K_{A}$ is the driver gain and $K_{t}$ is the torque constant.

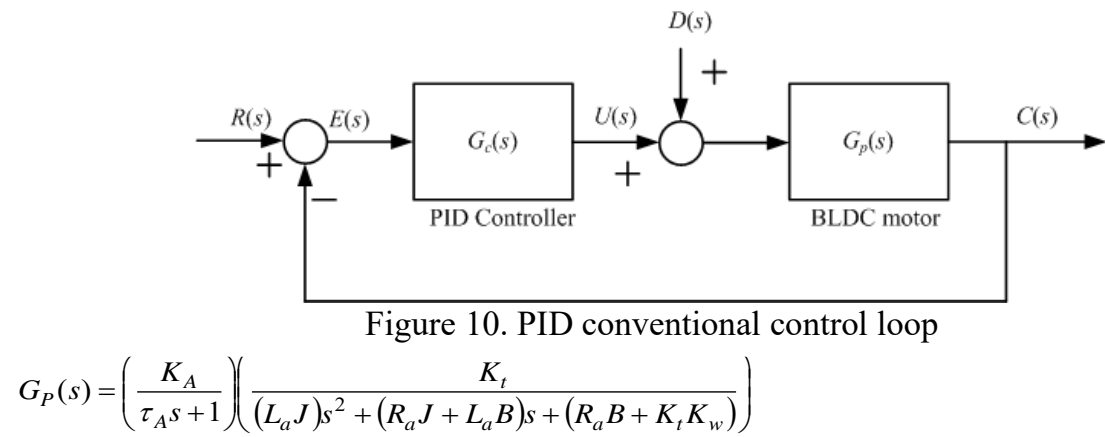

The PID controller model in the $s$-domain transfer function is stated in equation (7). Therefore, the PID controller can be written in the form of closed loop as shown in equation (8).

$$
\begin{aligned}
& G_{C}(s)=K_{P}+\frac{K_{i}}{s}+K_{d} s \\
& \frac{C(s)}{R(s)}=\frac{\left(K_{P}+\frac{K_{i}}{s}+K_{d} s\right) G_{P}(s)}{1+\left(K_{P}+\frac{K_{i}}{s}+K_{d} s\right) G_{P}(s)}
\end{aligned}
$$


The AI search techniques are applied to the PID controller design for the BLDC motor system as depicted in Figure 11. The objective function $\left(f_{o b j}\right)$, sum absolute-error (SAE) between $R(s)$ and $C(s)$ as stated in equation (9) will be fed back to the AI tuning block (ATS or ICS). The $f_{o b j}$ will be minimized by ATS or ICS to find the optimal PID parameters $\left(K_{p}, K_{i}\right.$ and $\left.K d\right)$ to satisfy the inequality constrainted functions as stated in equation (10), where $e_{s s}$ is steady-state error, $e_{s s_{-} \max }$ is maximum allowance of $e_{s s}, t_{r}$ is rise time, $t_{r_{-} \max }$ is maximum allowance of $t_{r}, M_{p}$ is maximum percent overshoot, $M_{p_{-} \max }$ is maximum allowance of $M_{p}, t_{s}$ is settling time, $t_{s_{-} \max }$ is maximum allowance of $t_{s}, K_{p_{-} \min }$ and $K_{p_{-} \max }$ are the search space of the $K_{p}, K_{i_{-} \min }$ and $K_{i_{-} \max }$ are the search space of the $K_{i}$ and $K_{d_{-} \min }$ and $K_{d_{-} \max }$ are the search space of the $K_{d}$. Flowcharts of ATS and ICS algorithms for the PID controller design optimization for the BLDC motor system are shown in Figure 12 and Figure 13, respectively.

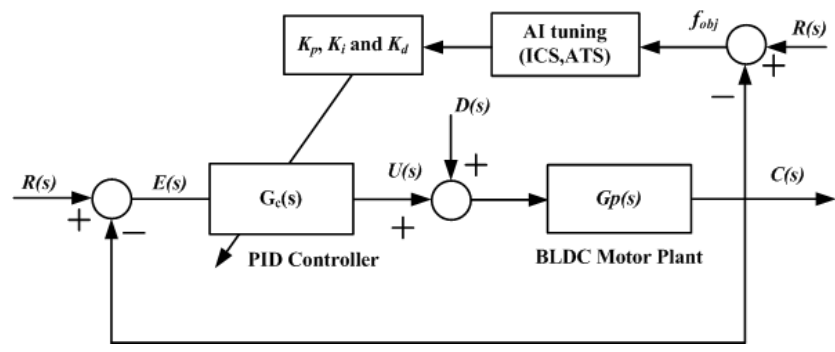

Figure 11. AI-based PID controller design.

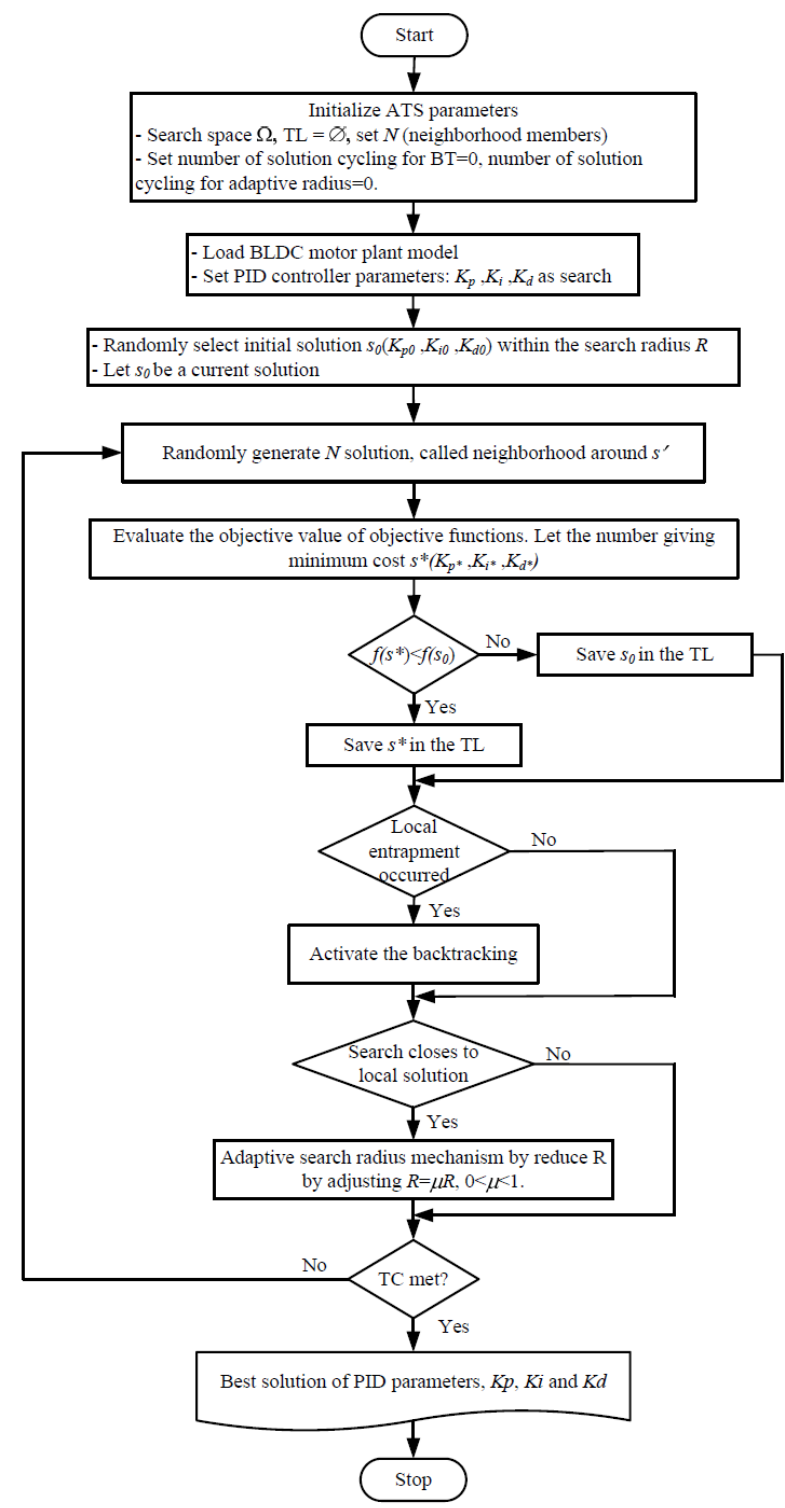


Figure 12. Flowchart of the ATS algorithm for PID controller design Minimize:

$$
f_{o b j}\left(K_{p}, K_{i}, K_{d}\right)=\sum_{i}^{N}[R(i)-C(i)]^{2}
$$

Subject to:

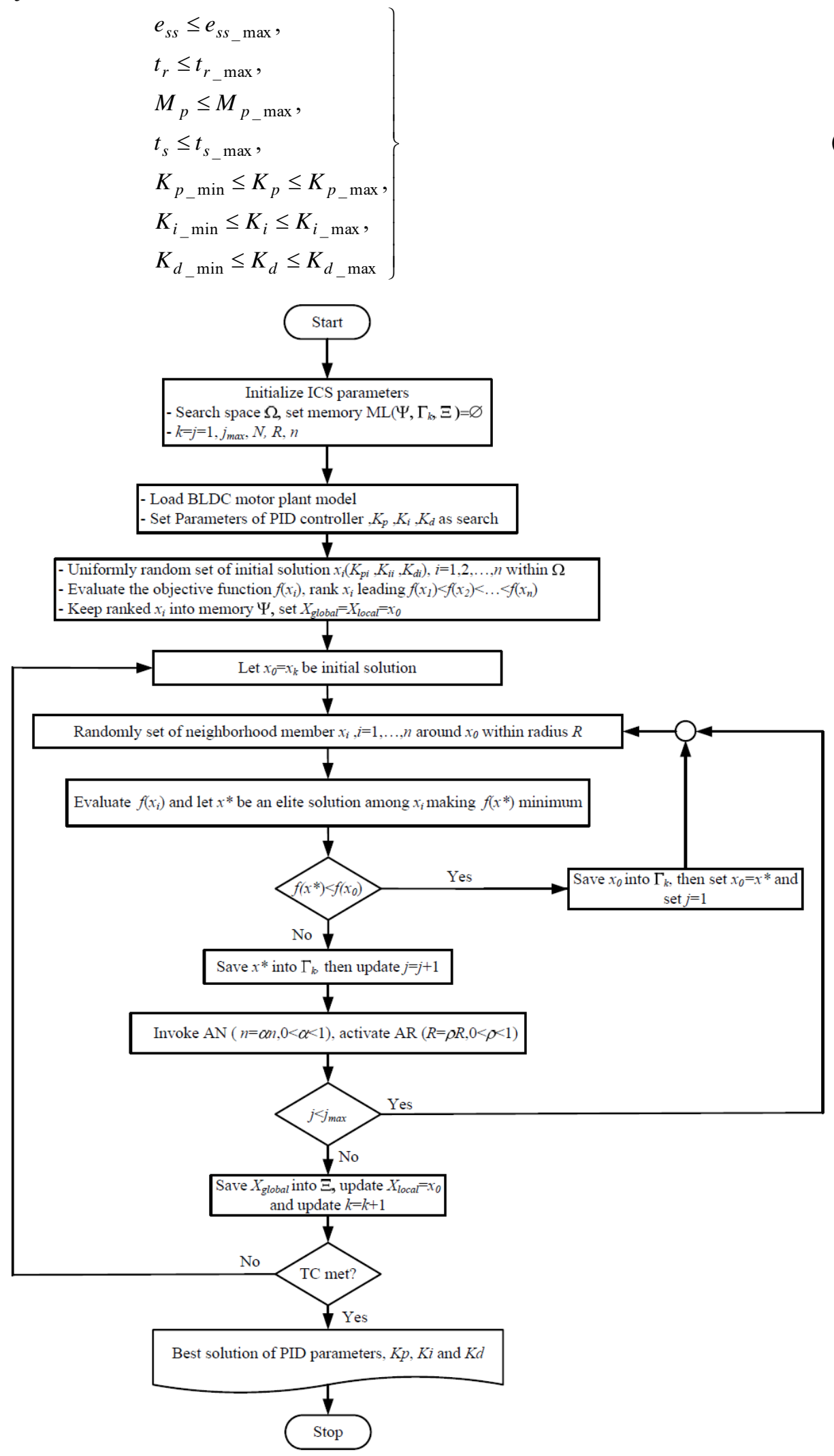


Figure 13. Flowchart of the ICS algorithm for PID controller design

\section{SIMULATION RESULTS}

The parameters of the BLDC motor plant were conducted as follows: $R_{a}=11.8183 \Omega, L_{a}=0.027 \mathrm{H}$, $J=0.0001 \mathrm{~kg}-\mathrm{m}^{2}, B=0.0003 \mathrm{~N} . \mathrm{m}-\mathrm{s} / \mathrm{rad}, K_{t}=0.2526 \mathrm{~N} . \mathrm{m} / \mathrm{A}, K_{w}=0.1319 \mathrm{~V} / \mathrm{rpm}, K_{A}=10.7615$ and $\tau_{A}=$ $0.0015 \mathrm{~s}$. Thus, the BLDC motor plant in equation (6) can be written in equation (11).

$$
G_{p}(s)=\frac{2.718}{4.05 \times 10^{-9} s^{3}+4.485 \times 10^{-6} s^{2}+1.245 \times 10^{-3} s+0.0368}
$$

Referring to Figure 11, the AI algorithms were simulated via MATLAB/ SIMULINK run on CPU Core i5, $2.5 \mathrm{GHz}$ and 6 Gbytes DDR-RAM computer. The optimal gains using AI techniques are setup. The design optimization by the ATS and ICS are performed as shown in Table 2 and Table 3, respectively. In addition, results obtained from the ATS and ICS will be compared with Ziegler-Nichols (ZN) tuning rule [28],[29] and GA [30]. The ZN tuning rule is the analytical design method, while the GA is one of the most popular metahueristic optimization techniques. However, both ZN and GA are not new anymore. Then, details of $\mathrm{ZN}$ and GA are omitted in this paper. Readers can find their details from the given references. The parameters of the GA are shown in Table 4. For design the PID controller, the search spaces of PID parameters in equation (10) are specified in Table 5.

Table 2. Parameters of ATS

\begin{tabular}{lc}
\hline Parameters & Values \\
\hline Number of iterations & 100 \\
Search radius & 0.5 \\
Number of neighborhood & 10 \\
Solution cycling & 10 \\
Back tracking & 5 \\
Adaptive radius: $f_{\text {obj }}<0.5, f_{o b j}<0.1, f_{o b j}<0.01$ & $0.25,0.1,0.01$ \\
\hline
\end{tabular}

Table 3. Parameters of ICS

\begin{tabular}{lc}
\hline Parameters & Values \\
\hline Number of iterations & 100 \\
Number of neighborhood & 10 \\
Number of search direction & 10 \\
Search radius & 0.5 \\
Solution cycling & 10 \\
Adaptive radius: $f_{o b j}<0.5, f_{o b j}<0.1, f_{o b j}<0.01$ & $0.25,0.1,0.01$ \\
Adaptive neighborhood: $f_{o b j}<0.5, f_{o b j}<0.1, f_{o b j}<0.01$ & $15,20,25$ \\
\hline
\end{tabular}

Table 4. Parameters of GA

\begin{tabular}{lc}
\hline Parameters & Values \\
Number of iterations & 100 \\
Number of population & 10 \\
Crossover rate & $95 \%$ \\
Mutation rate & $5 \%$ \\
Generation & 100 \\
\hline
\end{tabular}

Table 5. The search spaces of PID parameters

\begin{tabular}{lc}
\hline Parameters & Search space \\
\hline$K_{p}$ & $0-10$ \\
$K_{i}$ & $50-100$ \\
$K_{d}$ & $0-1$ \\
$t_{r_{-} \max }$ & $0.20 \mathrm{~s}$ \\
$M_{p_{-} \max }$ & $10 \%$ \\
$t_{s_{-} \max }$ & $0.30 \mathrm{~s}$ \\
$e_{s s_{-} \max }$ & $0.01 \%$ \\
\hline
\end{tabular}

The convergent rates of the proposed objective function in equation (9) and its corresponding inequality constrained functions in equation (10) proceeded by GA, ATS and ICS are depicted in Figure 14. The PID parameters of the BLDC motor system obtained by ZN tuning rule and optimized by GA, ATS and ICS are expressed in (12), (13), (14) and (15), respectively. The system responses of the BLDC motor without controller and with PID controllers are plotted in Figure 15 and summarized in Table 6. 


$$
\begin{aligned}
& \left.G_{C}(S)\right|_{P I D_{-} Z N}=4.527+\frac{66.473}{s}+0.425 s \\
& \left.G_{C}(S)\right|_{P I D_{-} G A}=3.326+\frac{71.210}{s}+0.035 s \\
& \left.G_{C}(S)\right|_{P I D_{-} A T S}=3.853+\frac{67.542}{s}+0.023 s \\
& \left.G_{C}(S)\right|_{P I D_{-} I C S}=4.135+\frac{64.261}{s}+0.021 s
\end{aligned}
$$

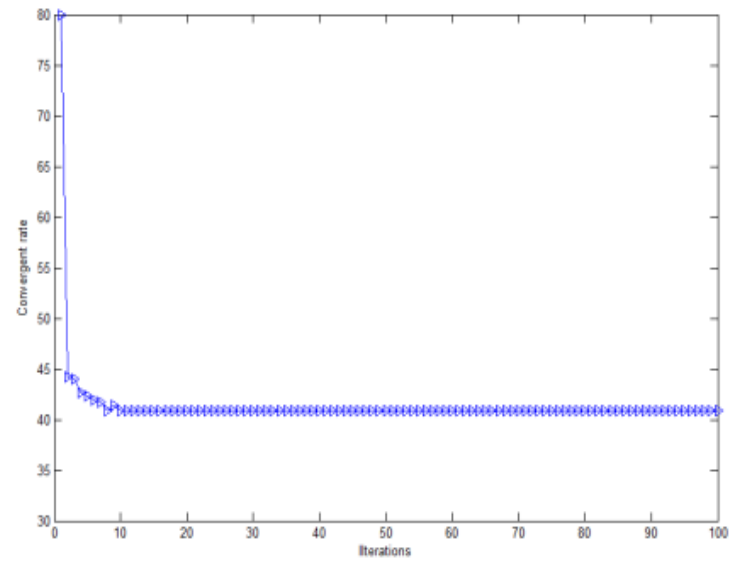

(a) GA

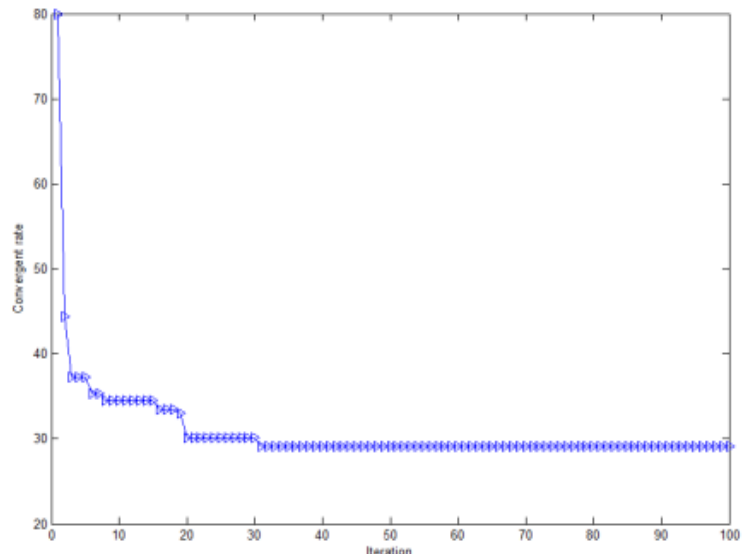

(b) ATS

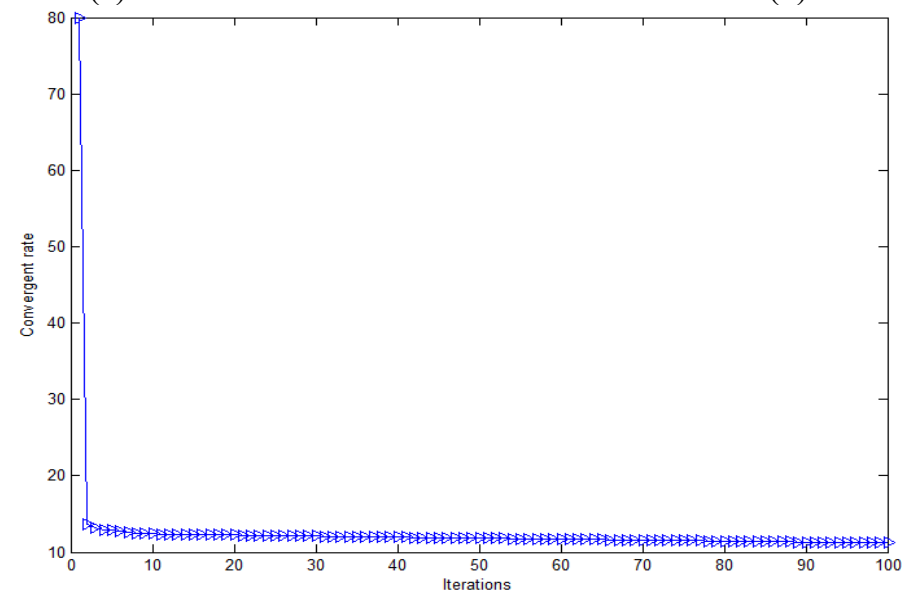

(c) ICS

Figure 14. Convergent rates of objective function

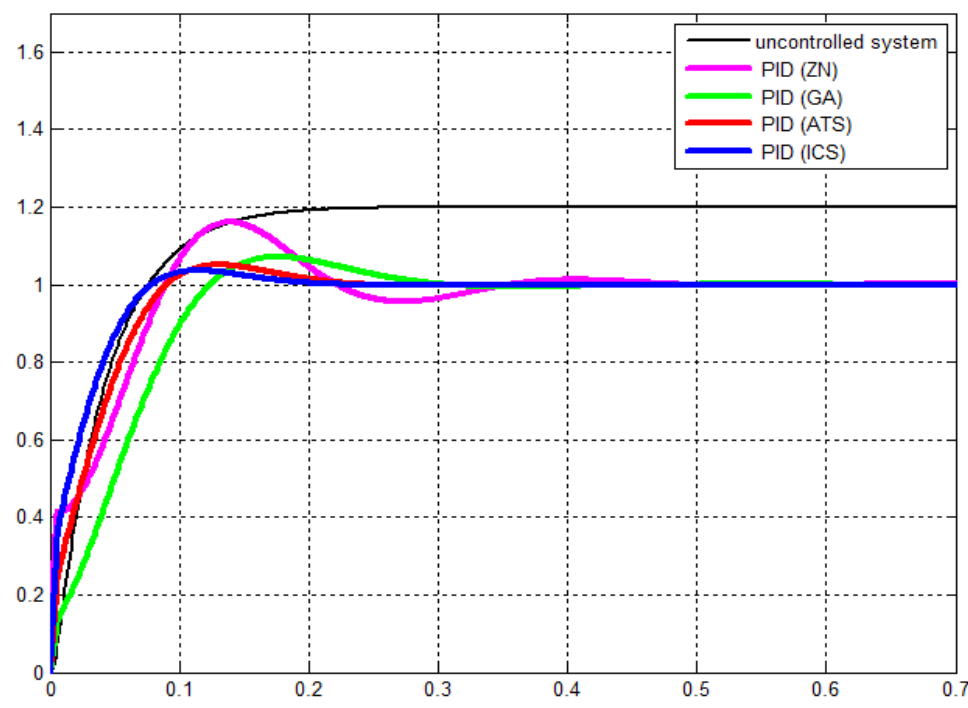

Artificial Intelligence-Based Optimal PID Controller Design for BLDC Motor... (M. Boonpramuk et al) 
Figure 15. System responses of PID controller Table 6. Performance of PID controller

\begin{tabular}{cccccc}
\hline Algorithms & \multicolumn{5}{c}{ Responses } \\
& $t_{r}(\mathrm{~s})$ & $M_{p}(\%)$ & $t_{s}(\mathrm{~s})$ & $e_{s s}(\%)$ & Search time (s) \\
\hline ZN & 0.0861 & 16.75 & 0.4761 & 0.00 & - \\
GA & 0.136 & 6.38 & 0.3150 & 0.00 & 27.253 \\
ATS & 0.0854 & 3.75 & 0.2083 & 0.00 & 18.582 \\
ICS & 0.0670 & 3.46 & 0.1538 & 0.00 & 14.427 \\
\hline
\end{tabular}

From to Figure 15 and Table 6, the performance with the PID controller optimized by the GA gives the slowest response. The system response with the PID controller obtained by the ZN tuning rule provides faster response but greater overshoot than that by the GA. The system response with the PID controller optimized by the ATS performs faster response and smaller overshoot than that by the GA and ZN tuning rule. However, the system response with the PID controller optimized by the ICS outperforms that by ZN tuning rule, GA and ATS with the fastest response and smallest overshoot according to inequality constrained functions in equation (10).

In addition, the BLDC motor speed control system with phase advance technique and the PID controllers obtained by the ZN tuning rule and optimized by the GA, ATS and ICS is simulated by MATLAB/SIMULINK as depicted in Figure 16. The BLDC motor in the simulink block diagram is a three phase motor rated 3,000 rpm. The effectiveness of the obtained PID controllers is analyzed under different operating conditions and compared with the conventional control of phase advance. Figure 17(a) depicts the responses of BLDC motor when speed changed from 0 to $2,800 \mathrm{rpm}$ with no load condition without phase advance. From the Figure 17(a), the responses of speed control are very satisfactory. Figure 17(b) shows the relation between the phase current $\left(i_{a}\right)$ and the back emf $\left(e_{a}\right)$. It was found that $i_{a}$ and $e_{a}$ are in phase.

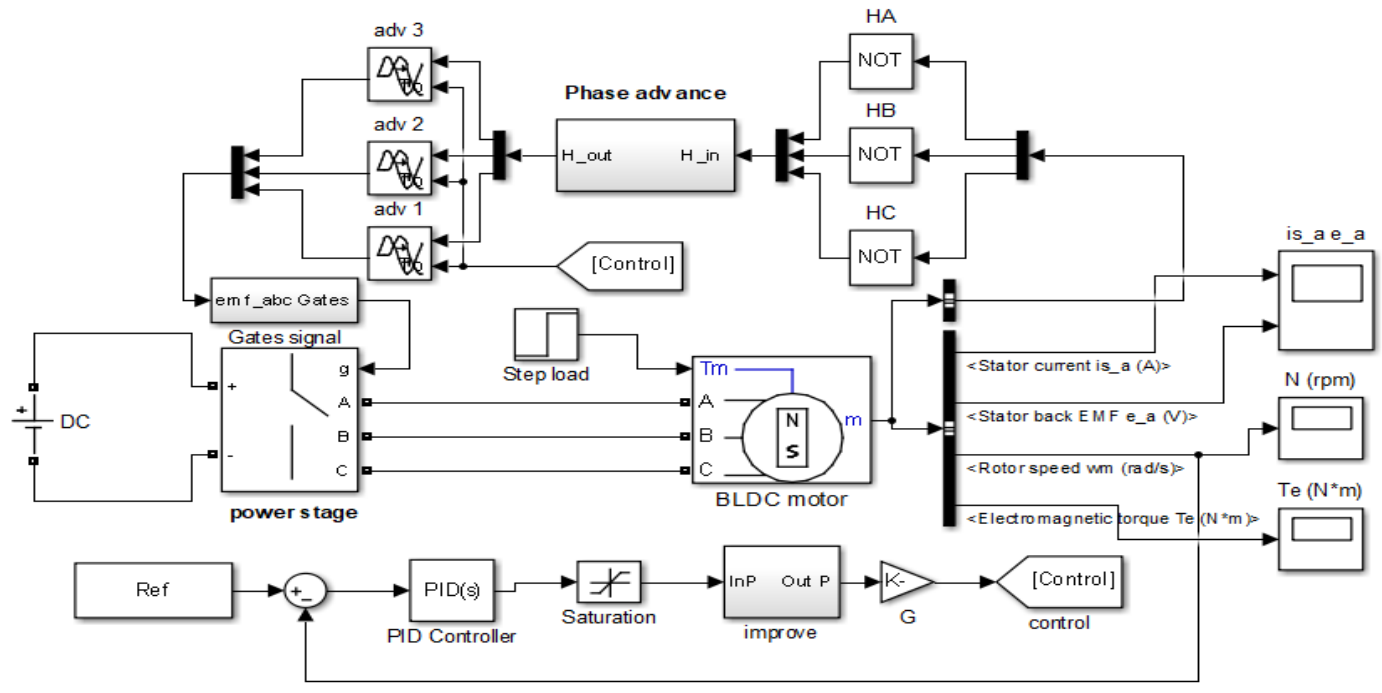

Figure 16. Simulink block diagram

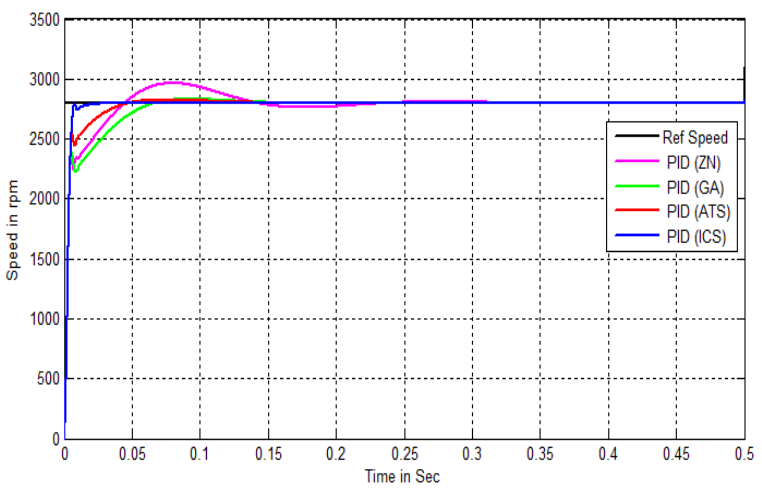

(a) Step change from 0 to $2,800 \mathrm{rpm}$

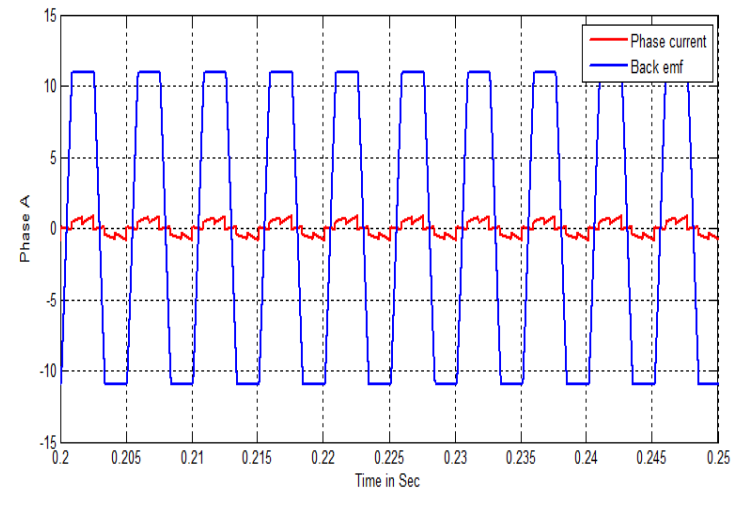

(b) Comparison between $i_{a}$ and $e_{a}$ 
Figure 17. Responses of BLDC motor speed control system without phase advance (no load)

Figure 18(a) depicts the responses of BLDC motor speed control system when speed changed from 2,800 to 3,100 rpm with no load condition with phase advance. From the figure 18(a), the BLDC motor system can extend the speed range over the 3,000 rpm. The speed response with the PID controller optimized by the ICS outperforms other controllers. Figure 18(b) depicts the relation between $i_{a}$ and $e_{a}$, it was found that $i_{a}$ leads $e_{a}$ at $0.5 \mathrm{~s}$.

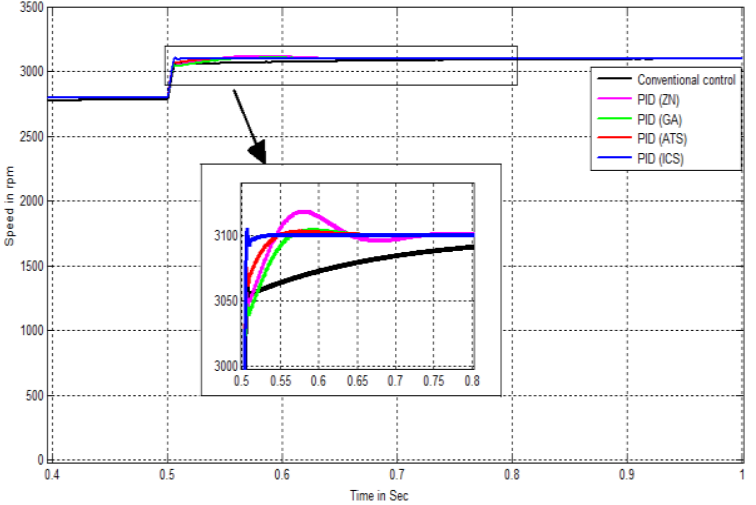

(a) Step change from 2,800 to $3,100 \mathrm{rpm}$

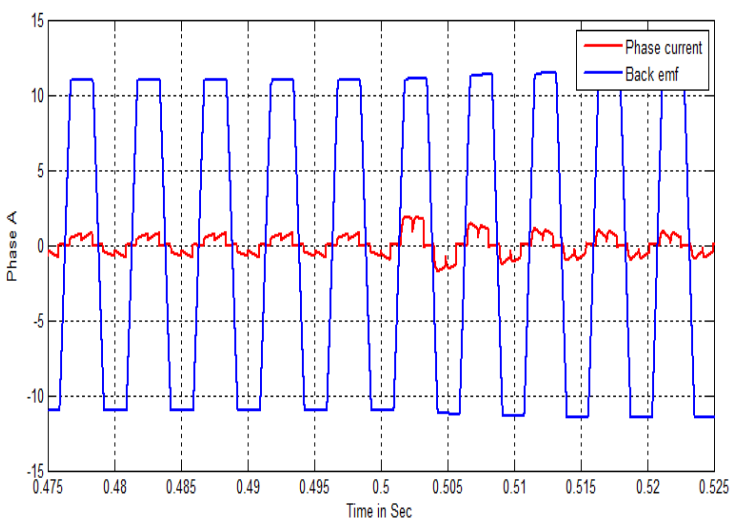

(b) Comparison between $i_{a}$ and $e_{a}$

Figure 18. Responses of BLDC motor speed control system with phase advance (no load)

Figure 19 depicts the responses of BLDC motor speed control system when speed changed from 3,100 to 2,800 rpm at $0.5 \mathrm{~s}$ with no load in Figure 19(a) and with load of 2 N.m in Figure 19(b). From Figure 19, the speed response with the PID controller optimized by the ICS also provides better response than other controllers with the least settling time of both no load and load.

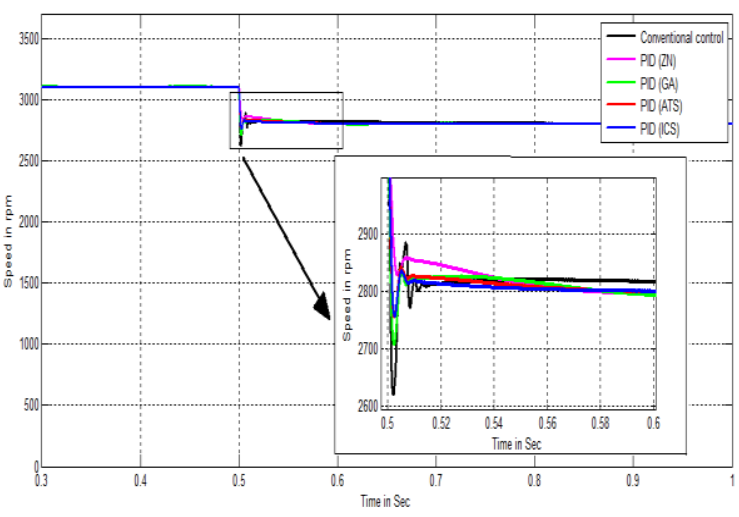

(a) No load

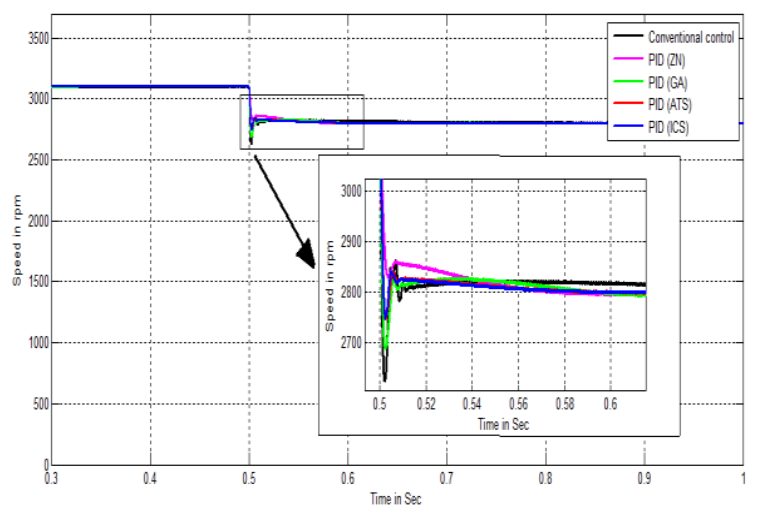

(b) Load of 2 N.m

Figure 19. Responses of BLDC motor speed control system with no load and on load of 2 N.m

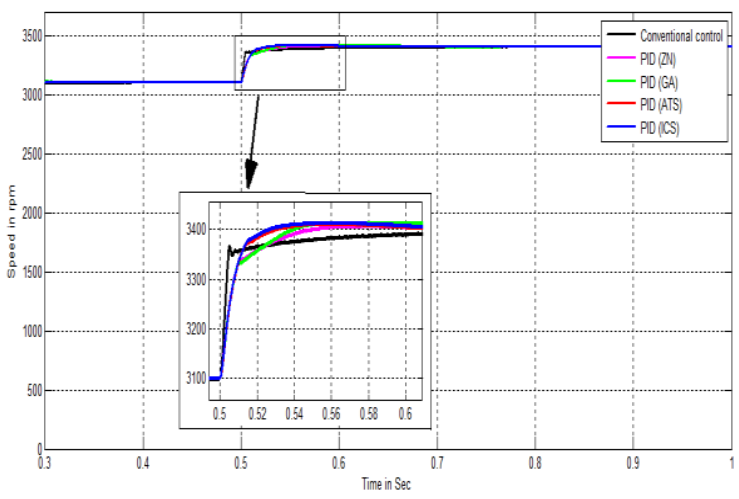

(a) Step change from 3,100 to 3,400 rpm

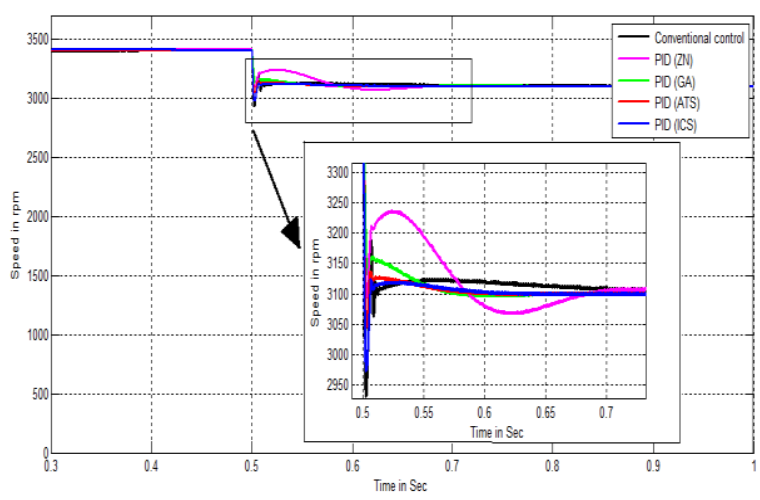

(b) Step change from 3,400 to 3,100 rpm

Figure 20. Responses of BLDC motor speed control system with phase advance at constant load of 2 N.m 
Figure 20(a) depicts the responses of BLDC motor speed control system with phase advance when speed changed from 3,100 to 3,400 rpm with constant load of 2 N.m. Figure 20(b) depicts the speed responses of BLDC motor speed control system with phase advance when speed changed from 3,400 to 3,100 rpm. From Figure 20, the speed response with the PID controller optimized by the ICS can yield better response than other controllers with the least settling time.

Figure 21 depicts the regulating responses of BLDC motor speed control system with phase advance at constant speed of 3,100 rpm with load of 2 N.m at $0.4 \mathrm{~s}$ and no load at $0.7 \mathrm{~s}$. From Figure 21, it was found that the speed responses once load applied and load released can be successfully controlled by the optimal PID controllers for load regulation purpose. For overall system performance, the PID controller optimized by the ICS for BLDC motor speed control system with phase advance outperforms other controllers.

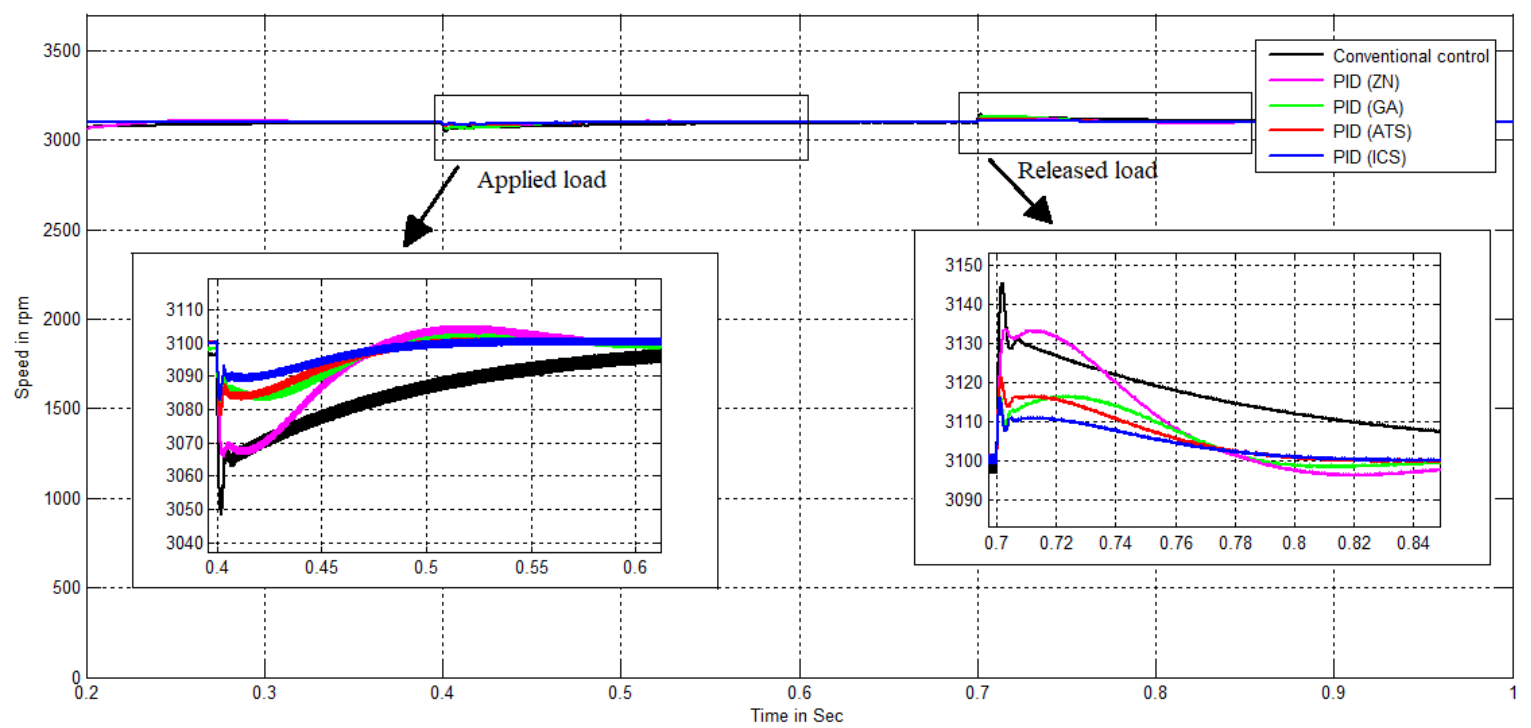

Figure 21. Responses of load regulation of BLDC speed control system

\section{CONCLUSION}

The AI-based optimal PID controller design optimization for BLDC motor speed control with phase advance has been presented in this paper. Two selected AI algorithms, i.e., the ATS and ICS, have been applied as the optimized to the PID controller design. In this paper, the mathematical model of the BLDC motor and the phase advance technique have been provided. Algorithms of the ATS and ICS have been clearly reviewed. The proposed design approach has been conducted by using MATLAB/SIMULINK. The PID controllers optimized by the ATS and ICS have been compared with the ZN tuning rule and the GA. As results, the ATS and ICS could successfully give optimal PID controllers. The simulation results shown that the responses of the BLDC motor speed control by phase advance with the PID controller designed by the ICS outperform that obtained by the ZN, GA and ATS, respectively. Moreover, the proposed ICS algorithm for PID controller design can be improved the system response effectively.

\section{REFERENCES}

[1] J. R. Hengershot and T. J. E. Miller, Design of Brushless Permanent Magnet Motor, Oxford Science, 1994.

[2] D. Hanselman, Brushless Permanent Magnet Motor Design, Magna Physics Publishing, 2006.

[3] S. Poonsawat and T. Kulworawanichpong, "Speed Regulation of a Small BLDC Motor using Genetic-Based Proportional Control," World Academy of Science, Engineering and Technology, vol. 2, no. 5, pp. 203-208, 2008

[4] M. S. bin Mohd and M. N. bin Karsiti, "Phase Angle Adjustment for Phase Advance Control of Brushless DC Motor," International Conference on Intelligent and Advanced Systems (ICIAS), pp. 1-6, 2014.

[5] K. Ang, G. Chong, and Y. Li, "PID Control System Analysis, Design and Technology," IEEE Transactions Control System Technology, vol. 13, no. 4, pp. 559-576, 2005.

[6] A. S. Othman and A. Mashakbeh, "Proportional Integral and Derivative Control of Brushless DC Motor," European Journal of Scientific Research, vol. 35, no. 4, pp. 198-203, 2009.

[7] A. Sharma, H. Negi and D. Punetha, "Adaptive Speed Control of BLDC Motor with Effective Starting and Minimized Cost and Core Loss," International Conference on Advances in Computing Communication and Automation, pp. 175-178, 2016. 
[8] J. J. Moon, W. S. Im and J. M. Kim, "Novel Phase Advance Method of BLDC Motors for Wide Range Speed Operations," Applied Power Electronics Conference and Exposition (APEC)-Eighth Annual IEEE, pp. 2343-2348, 2013.

[9] B. M. Nguyen and M. C. Ta, "Phase Advance Approach to Expand the Speed Range of Brushless DC Motor," International Conference on Power Electronics and Drive Systems, pp. 1255-1262, 2007.

[10] H. Kong, J. Liu and G. Cui, "Study on Field-Weakening Theory of Brushless DC Motor Based on Phase Advance Method," International Conference on Measuring Technology and Mechatronics Automation, pp. 583-586, 2010.

[11] S. I. Park, T. S. Kim, S. C. Ahn and D. S. Hyum, "An Improved Current Control Method for Torque Improvement of High-Speed BLDC Motor," Applied Power Electronics Conference and Exposition (APEC), pp. 294-299, 2003.

[12] K. N. Sujatha, K. Vaisakh and G. Anand, "Artificial Intelligence Based Speed Control of Brushless DC Motor," IEEE International Conference PES General Meeting, pp. 1-6, 2010.

[13] J. Mostafapour, J. Reshadat and M. Farsadi, "Improved Rotor Speed Brushless DC Motor Using Fuzzy Controller," Indonesian Journal of Electrical Engineering and Informatics(IJEEI), vol. 3, no. 2, pp. 78-88, 2015.

[14] S. Mehrdad and C. Greg, "An Adaptive PID Controller Based on Genetic Algorithm Processor," IEE Conference Genetic Algorithm in Engineering System, pp. 88-93, 1995.

[15] Y. Mitsukura, T. Yamamoto and M. Kaneda, "A Design of Self-tuning PID Controller using a Genetic Algorithm," The American Control Conference, 1999, pp. 1361-1365.

[16] D. Puangdownreong and S. Sujitjorn, "Obtaining an Optimum PID Controllers via Adaptive Tabu Search," International Conference on Adaptive and Natural Computing Algorithm, pp. 747-755, 2007.

[17] S. Khalid, "Optimized Aircraft Electric Control System Based on Adaptive Tabu Search Algorithm and Fuzzy Logic Control," Indonesian Journal of Electrical Engineering and Informatics(IJEEI), vol. 4, no. 3, pp 149-164, 2016.

[18] A. Sakulin and D. Puangdownreong, "Control Synthesis for Unstable Systems via Current Search," The WSEAS International Conference on Artificial Intelligence, pp. 131-136, 2012.

[19] D. Puangdownreong and A. Sukulin, "Obtaining an Optimum PID Controllers for Unstable Systems using Current Search," International Journal of Systems Engineering, Aplications \& Development, vol. 6, no. 2, pp. 188-195, 2012.

[20] A. Nawikavatan, S. Tunyasrirut and D. Puangdownreong, "Application of Intensified Current Search to Optimum PID Controller Design in AVR System," Asian Simulation Conference, pp. 255-266, 2014.

[21] D. Kumpanya, S. Thaiparnat and D. Puangdownreong, "Parameter Identification of BLDC Motor via Metaheuristic Optimization Techniques," International Conference on Industrial Engineering and Service Science, pp. 322-327, 2015.

[22] D. Puangdownreong, K. Areerak, A. Srikaew, S. Sujitjorn and P. Totarong, "System Identification via Adaptive Tabu Search,” IEEE International. Conference on Industrial Technology (ICIT'02), pp. 915-920, 2002.

[23] S. Sujitjorn, T. Kulworawanichpong, D. Puangdownreong and K.-N. Areerak, "Adaptive Tabu Search and Applications in Engineering Design," The 2006 conference on Integrated Intelligent Systems for Engineering Design, pp. 233-257, 2006.

[24] F. Glover, "Tabu Search Part I," ORSA Journal on Computing, vol. 1, no. 3, pp. 190-206, 1989.

[25] F. Glover, "Tabu Search Part II," ORSA Journal on Computing, vol. 2, no. 1, pp. 4-32, 1990.

[26] S. Bennett, "Development of the PID Controller," IEEE Control System Magazine, pp. 58-65, 1994.

[27] V. K. R. S. Patel and A. K. Pandey, "Modeling and Performance Analysis of PID Controlled BLDC Motor and Different Schemes of PWM Controlled BLDC Motor," International Journal of Scientific and Research Publications, vol. 3, no. 4, pp. 1-14, 2013.

[28] P. M. Meshram and R. G. Kanojiya, "Tuning of PID Controller using Ziegler-Nichols Method for Speed Control of DC Motor," International Conference On Advances In Engineering Science And Management, pp. 117-122, 2012.

[29] J. G. Ziegler and N. B. Nichols: Optimum Settings for AutomaticControllers, Trans. ASME, vol. 64, pp. 759-768, 1942.

[30] D. E Goldberg, Genetic Algorithms in Search, Optimization, and Machine Learning, Addison-Wesley, 1989. 